\title{
Antineutrophil Cytoplasmic Antibodies and Other Immunologic Abnormalities in Patients with Habitual Abortion
}

\author{
László Kovács, János Szabó, Katalin Molnár, Attila Kovács, and Gyula Pokorny
}

Kovács L, Szabó J, Molnár K, Kovács A, Pokorny G. Antineutrophil cytoplasmic antibodies and other immunologic abnormalities in patients with habitual abortion. AJRI 1999; 41:264-270 (C) Munksgaard, Copenhagen

PROBLEM: The immunologic mechanisms of pregnancy loss in habitual aborters with antiphospholipid and antinuclear antibodies have not been fully clarified. The possible association of antineutrophil cytoplasmic antibodies (ANCAs) with recurrent miscarriage was examined.

METHOD OF STUDY: In a prospective, controlled trial of 59 women with recurrent abortion, the prevalence of pANCA (antimyeloperoxidase), cANCA (antiproteinase3), and immunoserologic abnormalities of systemic lupus erythematosus (SLE) - antidouble-stranded DNA, anti-SSA, anti-SSB, anti-UIRNP, anti-Sm, anticardiolipin and antinuclear antibodies, LE-cell, lupus anticoagulant, and complement-3 - were investigated.

RESULTS: pANCA occurred in 2, and cANCA in 6 of 59 case patients, but neither was observed in the controls ( $P=0.09$ for cANCA). cANCA levels were significantly higher in patients than in controls $(P=0.028)$. Six recurrent aborters were identified as having a group of immunoserologic abnormalities characteristic of SLE.

CONCLUSIONS: Immunologic mechanisms detectable in SLE may operate in a subgroup of habitual aborters with suspected immunologic cause. ANCAs occur more frequently in patients with recurrent miscarriage than in controls.

\section{INTRODUCTION}

Antiphospholipid antibodies have been reported to be associated with idiopathic habitual abortion. ${ }^{1-7}$ and recent investigations have also demonstrated their value for the prediction of an adverse outcome in subsequent preg-
Key words:

Antineutrophil cytoplasmic antibodies, antiphospholipid antibodies, habitual abortion, systemic lupus erythematosus

\section{LÁSZLÓ KOVÁCS \\ JÁNOS SZABÓ}

First Department of Internal

Medicine, Department of Medical Genetics, Albert Szent-Györgyi Medical University, Szeged, Hungary

\section{KATALIN MOLNÁR}

Department of Dermatology, Albert Szent-Györgyi Medical University, Szeged, Hungary

\section{ATTILA KOVÁCS GYULA POKORNY \\ Blood Transfusion Center, First Department of Internal Medicine, Albert Szent-Györgyi Medical University, Szeged, Hungary}

Address reprint requests to László Kovács, M.D., First Department of Internal Medicine, Albert Szent-Györgyi Medical University, P.O. Box 469, Szeged, H-6701. Hungary.

Submitted June 29. 1998; accepted August 24. 1998. 
nancy. ${ }^{2.4} \mathrm{~A}$ relationship has also been revealed between the presence of antinuclear antibodies and recurrent miscarriage, although data are far less consistent. $^{7-10}$ Thyroid and antimitochondrial antibodies have also been investigated in connection with recurrent miscarriage." The pathomechanism by which these antibodies may cause fetal death is by no means clear. It is believed by some that the autoantibodies may be only an epiphenomenon reflecting a separate underlying immunologic mechanism. ${ }^{12}$

In systemic lupus erythematosus (SLE), an increased rate of spontaneous abortions may be observed even before the onset of the classical symptoms of the disease. ${ }^{13}$ Therefore, we have started a study of women with idiopathic recurrent spontaneous abortion with the aim of investigating a wide spectrum of immunoserologic markers occurring in patients with SLE, and intend to follow up these patients for a long period. We wish to answer the question of whether the underlying immunologic disorder may be regarded as a preclinical SLE or a related, nonclassified systemic autoimmune disease.

Systemic vasculitides constitute another group of systemic autoimmune diseases. Antineutrophil cytoplasmic antibodies (ANCAs) are useful tools in the diagnosis of certain types of systemic vasculitides, especially Wegener's granulomatosis, microscopic polyangiitis, and Churg-Strauss syndrome, and they occur in other autoimmune diseases too, such as SLE. ${ }^{14.15}$ As far as we are aware, they have not been investigated previously in the context of habitual abortion. We therefore examined their prevalence among our study patients.

\section{MATERIALS AND METHODS}

The study involved 59 women with a history of at least two consecutive spontaneous abortions in pregnancies from the same partner. Their average age was 30.47 years (range 19-47 years). Genetic, endocrine, anatomical, infectious, and internal medical causes of habitual abortion were excluded. None of the patients had a clinically obvious systemic autoimmune disease or a chronic medical illness. Eighteen of the 59 women had a prior pregnancy ending in a live delivery. Seven patients had pregnancies with two partners. Two of them had at least two consecutive fetal losses with both partners. One patient had two miscarriages with the first partner and one further spontaneous abortion with the second. The remaining four women all had their miscarriages with the second partner, and normal pregnancies with the first. The patients were not receiving any regular medication at the time of the examinations.

The control group comprised 25 healthy women with no history of fetal loss. All of them had at least two successful pregnancies before the blood sampling. Their average age was 30.08 years (range 21-37 years).

A comparison of the obstetric data on the women in the two groups is presented in Table I. Spontaneous abortion was defined as pregnancy loss before the twenty-eighth completed week of gestation. Two intrauterine deaths occurred in two patients in the thirty-fifth or thirty-eighth week of gestation. The term fetal loss is therefore used to cover both spontaneous abortions and late intrauterine deaths. Three infants died after live births in the twenty-fifth, twenty-sixth or twenty-seventh week of gestation, and

TABLE I. Age and Obstetric History of Habitual Abortion Patients and Normal Controls ${ }^{a}$

\begin{tabular}{|c|c|c|}
\hline & $\begin{array}{l}\text { Habitual abortion } \\
(n=59)\end{array}$ & Control $(n=25)$ \\
\hline Age (years, mean $\pm S D$, range) & $30.47 \pm 5.68,19-47$ & $\begin{array}{l}30.08 \pm 5.33 \\
21-37\end{array}$ \\
\hline No. of previous pregnancies (mean $\pm \mathrm{SD}$, range) ${ }^{*}$ & $3.51 \pm 1.56,2-9$ & $\begin{array}{l}2.44 \pm 0.71 \\
2-5\end{array}$ \\
\hline No. of previous live deliveries (mean $\pm S D$, range) & $0.41 \pm 0.62,0-2$ & $\begin{array}{l}2.16 \pm 0.37 \\
2-5\end{array}$ \\
\hline No. of previous fetal losses (overall) (mean $\pm S D$, range) & $2.76 \pm 1.21,2-8$ & 0 \\
\hline $\begin{array}{l}\text { No. of previous second-trimester spontaneous abortions (mean } \pm S D \text {, } \\
\text { range) }\end{array}$ & $0.63 \pm 0.71,0-4$ & 0 \\
\hline No. of previous induced abortions (mean $\pm S D$, range) & $0.31 \pm 0.59,0-2$ & $\begin{array}{l}0.20 \pm 0.41 \\
0-1\end{array}$ \\
\hline
\end{tabular}

\footnotetext{
"Age. number of previous pregnancies. and momber of previous indaced abortions were compared statistically. SD. stamkard deriation.

$* P<0.05$.
} 
one infant born at term died 1 day after delivery. Induced abortions were performed before the twelfth week of gestation for reasons other than medical ones. Blood was taken in the nonpregnant state from persons in both groups.

Laboratory techniques included indirect immunofluorescence for the detection of antinuclear antibodies: rotatory method utilizing heparin and glass beads for lupus erythematosus (LE) cell investigation; rocket immunoelectrophoresis for the measurement of complement-3 levels; complement consumption test to assess circulating immunocomplexes (CICs); determination of activated partial thromboplastin time for the detection of lupus anticoagulant (LAC): and enzymelinked immunosorbent assays (ELISAs) to detect anticardiolipin (aCL) immunoglobulin G (IgG) (Shield Diagnostics, Dundee, UK), anti-double-stranded DNA (anti-dsDNA), anti-SSA, anti-SSB, anti-Sm. and anti-U1RNP (Epignost, Leonding/Linz, Austria) autoantibodies. Evaluation of CANCA was performed with an ELISA using proteinase-3 (PR-3) as antigen. while the presence of pANCA was assessed with an anti-myeloperoxidase (anti-MPO) ELISA (Shield Diagnostics, Dundee, UK). Precoated ELISA kits were used in accordance with the manufacturer's instructions. Cases were considered to involve LE-cell positivity when typical LE cells or the characteristic round. homogenous hematoxylin bodies were observed. This examination was not performed in four of the study patients. Similarly, LAC was not examined in seven of the study patients.

The Student's $t$-test was used in comparisons of age and of the numbers of previous pregnancies, deliveries, and induced abortions between the study and control groups. The $\chi^{2}$ test or Fisher's exact test were applied in comparisons of the frequencies of various immunologic variables between the two groups. For the comparison of the cANCA levels, the Mann-Whitney $\mathrm{U}$-test was applied.

\section{RESULTS}

The most common serologic markers used in the diagnosis and follow-up of SLE were examined in both groups. The frequencies of anti-dsDNA, antiSSA. anti-SSB, anti-Sm, anti-U1RNP, anti-cardiolipin IgG autoantibodies; the lupus anticoagulant: LE cell: antinuclear antibodies: and decreased complement-3 levels in women suffering habitual abortion and in healthy control women are presented in Table II. For $\mathrm{aCL}$. the prevalences of markedly elevated levels (more than 2.5 times higher than the upper limit of the normal range) are also presented. Although aCL and LAC occurred more frequently in habitual
TABLE II. Frequencies of Immunologic Changes in Habitual Abortion Patients and in Normal Controls"

\begin{tabular}{lll}
\hline & $\begin{array}{l}\text { Habitual } \\
\text { abortion (\%) }\end{array}$ & Control (\%) \\
\hline Antinuclear antibodies & $259(3.39)$ & $225(8.0)$ \\
Anti-dsDNA & $259(3.39)$ & $2.25(8.0)$ \\
Anti-SSA & $159(1.69)$ & 0.25 \\
Anti-SSB & $159(1.69)$ & 0.25 \\
Anti-Sm & 0.59 & 0.25 \\
$\begin{array}{l}\text { Anti-U1RNP } \\
\text { Anti-cardiolipin }\end{array}$ & 0.59 & 0.25 \\
$\begin{array}{l}\text { Anti-cardiolipin moderate } \\
\text { to high positive }\end{array}$ & $559(8.47)$ & 0.25 \\
$\begin{array}{l}\text { Lupus anticoagulant } \\
\text { Lupus erythematosus }\end{array}$ & $652(11.54)$ & $1.22(4.54)$ \\
$\quad$ cell & $655(10.91)$ & $125(4.0)$ \\
Decreased & $1259(20.34)$ & $4.25(16.0)$ \\
$\quad$ complement-3 & $259(3.39)$ & 0.25 \\
pANCA & $659(10.17)$ & 0.25 \\
cANCA* & & $4.25(16.0)$ \\
\end{tabular}

"Numbers indicate positivity total number of subjects examined. with frequencies in brackets. For the other examined cartables. no signiticant difference was found between the wio groups.

${ }^{*} P=0.09$.

aborters, and markedly elevated levels of aCL were found only in the study group (in five patients), no significant differences were observed in the prevalences of the examined serologic variables between the two groups.

pANCA was found in 2/59 examined patients but in none of the controls, while cANCA was found in 659 examined patients but none of the controls. This latter difference approaches, but does not quite reach, the level of statistical significance $(P=0.09)$. However, when the levels of cANCA were compared in the two groups, statistically higher values were revealed in the habitual abortion patients than in the healthy persons $(P=0.028)$. The titers of both ANCA types were in the low and the moderately high range (maximum 2.5 times higher than the upper limit of the normal range) in the patient group. The distribution of the autoantibody levels in the study group is to be seen in Fig. 1. A comparison of the cANCA levels in the habitual abortion patients and the controls is represented in Table III and Fig. 2. A similar comparison did not reveal a difference in the pANCA titers (data not shown). The serologic characteristics and obstetric histories of the eight patients with either pANCA or cANCA positivity are summarized in Table IV. The age and the obstetric history data do not differ significantly from those for the overall group of habitual 
aborters. In half of these eight patients, no other immunoserologic abnormality was revealed, while the other four patients were positive for aCL. Statistical analysis did not confirm that ANCA positivity is more likely in patients with aCL.

Among the 59 patients with recurrent abortion, 28 proved positive for at least one of the examined laboratory variables. The majority exhibited only one positive value, most often an increased aCL antibody titer. However, six patients displayed a wide spectrum of laboratory abnormalities. The findings on these six patients are presented in Table $\mathrm{V}$. None of them were positive for either pANCA or cANCA. The reproductive performances of these 6 women were as follows: 27 pregnancies $(4.5$ person $)$, three live deliveries $(0.5$ person), 21 spontaneous abortions (3.5/person), and three induced abortions $(0.5 /$ person). No fetal loss occurred after the twenty-eighth gestational week. These data do not differ significantly from those for the overall group of habitual aborters. It should be noted that patient 6 experienced eight consecutive spontaneous abortions after a normal delivery, six from the first and two from a second partner. Two other women had recurrent abortions with two male partners; one of these women had a decreased complement-3 level, while the other had no immunoserologic abnormality.

\section{DISCUSSION}

It is widely accepted that antiphospholipid antibodies (including aCL and LAC), and possibly antinuclear antibodies, are in some way associated with recurrent abortion. The underlying immunologic mechanism has been the subject of numerous examinations involving different approaches. ${ }^{16-19}$ In the present study we examined a number of immunologic abnormalities on which the evaluation of patients with SLE is based.

Although the prevalence of $\mathrm{aCL}$ and $\mathrm{LAC}$ was higher in patients with recurrent abortion than in the controls, and high titers of aCL were detected only in the study group, no difference proved significant.
Antinuclear antibodies were detected in small numbers of patients in both groups, while LE cell and decreased complement-3 levels were not infrequent in patients with recurrent miscarriage. although again without statistical significance. In 31 of the patients, no immunologic positivity was found at all, whereas 6 otherwise asymptomatic habitual aborters could be identified in whom an association of multiple immunologic abnormalities was revealed. The presence of this spectrum of autoimmune abnormalities, detectable at the same time, is very uncommon in otherwise asymptomatic persons. This laboratory constellation warrants further investigations; in persons with some clinical symptoms it would be highly suggestive of SLE.

The question of whether recurrent miscarriage may be the first clinical sign of SLE has been addressed previously, ${ }^{8}$ and it was concluded that the answer was negative. However, in that study, fewer immunologic markers were investigated, and the follow-up population (patients with antinuclear antibody positivity) was somewhat different from the present one. On the other hand, after the detection of anti-dsDNA in otherwise healthy individuals, $85 \%$ of them developed clinically overt SLE within a few years. ${ }^{20}$ In another study, in a high proportion of anti-SSA or anti-SSB positive mothers of children with isolated congenital heart block, symptoms of primary Sjögren's syndrome developed at varying times after delivery. ${ }^{21}$ Therefore, we feel that it is worthwhile to follow up these patients, especially those with multiple autoimmune laboratory abnormalities, with special attention to the development of signs and symptoms of SLE or of other systemic autoimmune diseases. The question we wish to answer is whether immunologic processes suspected of being involved in the pathogenesis of SLE may be underlying factors implicated in the elicitation of an adverse pregnancy outcome in a specific subgroup of patients with habitual abortion. The further investigation of specific T-cell abnormalities is essential in this regard. $22-25$

Systemic vasculitides constitute a heterogenous family of systemic autoimmune diseases. ANCA is a

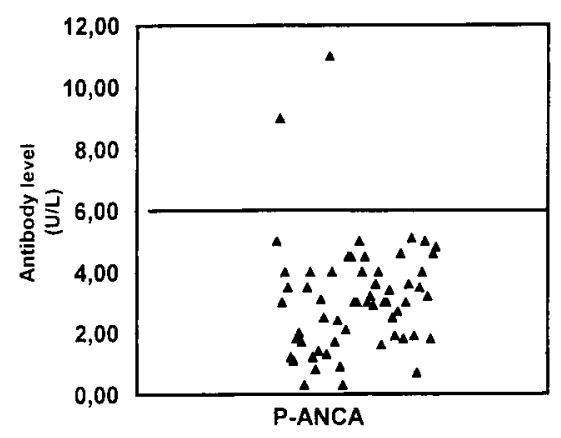

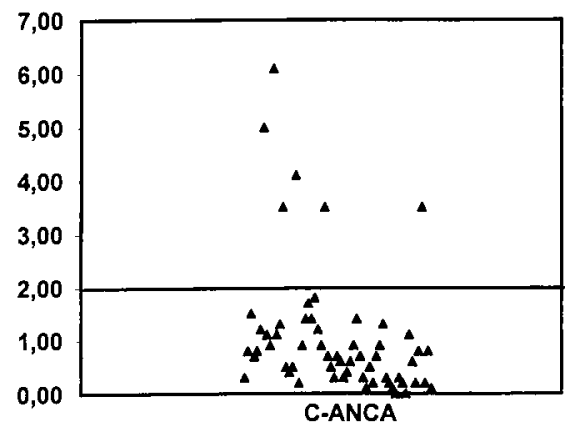

Fig. 1. Distribution of antimyeloperoxidase (pANCA) and antiproteinase-3 (cANCA) antibodies in patients with recurrent abortion. Values below the lines are negative. 
TABLE III. Comparison of CANCA Levels in Patients with Recurrent Abortion $(n=59)$ and in Controls $(n=25)$

\begin{tabular}{llccccc}
\hline & \multicolumn{2}{l}{ Antibody titers $(U$ L) } \\
& Mean & SD & SE & Median & Min & Max \\
\hline Habitual abortion & 0.81 & 1.22 & 0.16 & 0.40 & 0.10 & 6.00 \\
Control & 0.32 & 0.13 & 0.03 & 0.30 & 0.10 & 0.60 \\
\hline
\end{tabular}

$P=0.028$

SD. standard deriation: SE. standard error: Min. minimum ralus: Max. maximum rahte.

useful diagnostic aid in some types of systemic vasculitides. with pANCA being prevalent in microscopic polyangiitis and Churg-Strauss syndrome, and cANCA in Wegener's granulomatosis. It can also occasionally be found in various autoimmune and inflammatory diseases, such as SLE, drug-induced lupus, inflammatory bowel diseases. idiopathic rapidly progressive glomerulonephritis. or chronic viral hepatitis. The major antigen in patients with ANCA with perinuclear staining (pANCA) is myeloperoxidase. while in those with diffuse cytoplasmic staining (cANCA) it is proteinase-3. We detected ANCA in eight patients with recurrent miscarriage (pANCA in 2 and CANCA in 6) and in none of the controls. The higher prevalence of CANCA (though the difference is of only borderline statistical significance) and the higher cANCA levels raise the possibility that this autoantibody may in some way be associated with

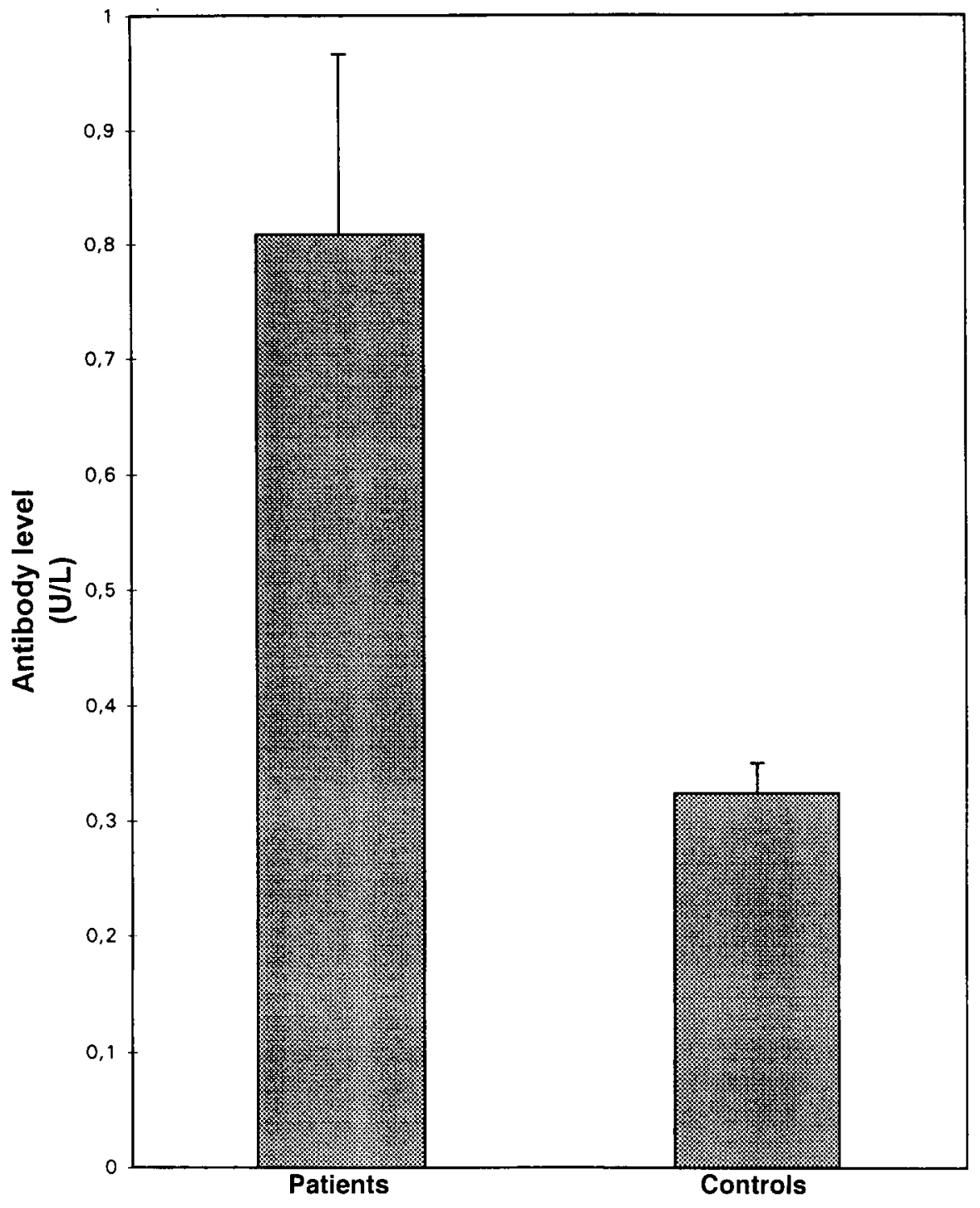

Fig. 2. A comparison of CANCA lesels in patients with habitual abortion and in healthy controls. Bars show mean \pm SE. $P=0.028$. 
TABLE IV. Associated Laboratory Abnormalities, Obstetric History, and Age of Antineutrophil Cytoplasmic Antibody (ANCA) Positive, Recurrent Abortion Patients"

\begin{tabular}{|c|c|c|c|c|c|c|c|}
\hline \multirow[b]{2}{*}{ Patient } & & \multirow[b]{2}{*}{ Associated laboratory abnormality } & \multirow[b]{2}{*}{$\mathrm{G}$} & \multirow[b]{2}{*}{$\mathrm{P}$} & \multicolumn{2}{|c|}{ Fetal loss (trimester) } & \multirow[b]{2}{*}{ Age } \\
\hline & & & & & 1st & 2nd & \\
\hline 1 & pANCA & $\mathrm{aCL}$ & 3 & 1 & 2 & 0 & 33 \\
\hline 2 & pANCA & - & 3 & 0 & 2 & 0 & 39 \\
\hline 3 & CANCA & $\mathrm{aCL}$ & 5 & 2 & 2 & 1 & 42 \\
\hline 4 & CANCA & - & 3 & 0 & 3 & 0 & 28 \\
\hline 5 & CANCA & $\mathrm{aCL}, \mathrm{CIC}$ & 8 & 0 & 5 & 1 & 28 \\
\hline 6 & CANCA & $\mathrm{aCL}, \mathrm{ClC}$ & 4 & 0 & 0 & 4 & 31 \\
\hline 7 & CANCA & - & 5 & 1 & 3 & 1 & 26 \\
\hline 8 & CANCA & - & 2 & 0 & 2 & 0 & 22 \\
\hline
\end{tabular}

"Indeced ahertions are not included in the table. No third-trimester fetal losses occurred in these parients. Age and obstetrical data do not differ significuntly firom those in the ocerall group of habitual ahorters.

G. number of pretions gestations: P. number of pretious lite deticeries.

recurrent abortion. ANCA levels in the study patients are lower than those observed in patients with active systemic vasculitis, and similar to the levels described in studies of patients with SLE. Patients with ANCA did not constitute a specific group in respect of age. the number of previous pregnancies. or the number or duration of gestation of the previous miscarriages as compared with the overall group of patients.

In some inflammatory diseases. ANCAs may arise as a result of polyclonal immune activation, but in our patients no statistically significant association of ANCA with any other autoantibodies was revealed. In fact. except for aCL, no other autoantibodies were found in ANCA positive patients. It may be interesting that none of the six patients with multiple autoimmune laboratory changes had ANCA. and. vice versa. ANCA positive patients had relatively few associated

TABLE V. Laboratory Characteristics of Six Patients Selected Because of the Presence of an Association of Multiple Autoimmune Serologic Abnormalities

\section{Patient}

\begin{tabular}{lllll}
\hline 1 & LE cell & C-3 $\downarrow$ & LAC & CIC \\
2 & Anti-SSA & Anti-SSB & C-3 $\downarrow$ & CIC \\
3 & Anti-dsDNA & aCL & CIC & \\
4 & LE cell & LAC & & \\
5 & aCL & LAC & C-3 $\downarrow$ & CIC \\
6 & ANA & C-3 $\downarrow$ & Leukopenia & \\
\hline
\end{tabular}

LE. hupus orrthematesus: C-31. decreased complement-3: L.4C: lupus anticoagulemt: CIC. circulating immumocomplexes: aCL. anticardiolipin: AN.A. antinuclear amihods. laboratory abnormalities. While this may be a coincidence, it may also raise the question of whether the reported immunologic findings indicate distinct immunologic pathomechanisms of repeated abortion in the patients in these two subgroups.

One widely-accepted theory ${ }^{26}$ is that the activation of neutrophil granulocytes and endothelial cells by certain cytokines is followed by the translocation of proteinase- 3 to the cell surface, where it binds antiproteinase-3, thereby leading to endothelial injury, intravascular lysis of neutrophils, and microvascular damage. This process remains to be investigated in the endometrium during implantation and placentation.

The questions of whether the presence of ANCA, especially of cANCA, has a specific role in habitual abortion. and whether it is of clinical importance in reproductive immunology must be answered after the follow-up of our patients and further examinations.

\section{Acknowledgments}

This work was supported by a grant from the $\mathrm{Na}$ tional Scientific Research Fund of Hungary (OTKA T 017 482).

\section{REFERENCES}

I. Cowchock S. Dehoratius R. Wapner RJ. Jackson LG: Subclinical autoimmune disease and unexplained abortion. Am J Obstet Gynecol 1984: 150:367-371.

2. Out HJ. Bruinse HW. Christiaens GCML, van Vliet M. de Groot PG, Nieuwenhuis K. Derksen RHWM: A prospective. controlled multicenter study on the obstetric risks of pregnant women with antiphospholipid antibodies. Am J Obstet Gynecol 1992: 167:26 - 32. 
3. Rai RS. Regan L, Clifford K, Pickering W, Dave M. Mackie I. McNally T. Cohen H: Antiphospholipid antibodies and beta2-glycoprotein-I in 500 women with recurrent miscarriage: Results of a comprehensive screening approach. Hum Reprod 1995: 10:2001-2005.

4. Rai RS. Clifford K. Cohen H. Regan L: High prospective fetal loss rate in untreated pregnancies of women with recurrent miscarriage and antiphospholipid antibodies. Hum Reprod 1995: 10:3301-3304.

5. Taylor M. Cauchi MN. Buchanan RR: The lupus anticoagulant, anticardiolipin antibodies. and recurrent miscarriage. Am J Reprod Immunol 1990: 23:33-36.

6. Oshiro BT, Silver RM, Scott JR, Yu H, Branch DW: Antiphospholipid antibodies and fetal death. Obstet Gynecol 1996: 87:489-493.

7. Petri M. Golbus M. Anderson R, Whiting-O'Keefe Q, Corash L. Hellmann D: Antinuclear antibody. lupus anticoagulant, and anticardiolipin antibody in women with idiopathic habitual abortion: A controlled. prospective study of forty-four women. Arthritis Rheum 1987; 30:601-606.

8. Harger JH, Rabin BS, Marchese SG: The prognostic value of antinuclear antibodies in women with recurrent pregnancy losses: A prospective controlled study. Obstet Gynecol 1989: 73:419-424.

9. Xu L. Chang V, Murphy A, Rock JA. Damewood M. Schlaff W, Zacur H: Antinuclear antibodies in sera of patients with recurrent pregnancy wastage. Am J Obstet Gynecol 1990; 163:1493-1497.

10. Ogasawara M, Aoki K. Kajiura S. Yagami Y: Are antinuclear antibodies predictive of recurrent miscarriage? Lancet 1996; 347:1183-1184.

11. Roberts J, Jenkins C. Wilson R. Pearson C, Franklin IA. MacLean MA, McKillop JH. Walker JJ: Recurrent miscarriage is associated with increased numbers of CD5 20 positive lymphocytes and an increased incidence of thyroid antibodies. Eur J Endocrinol 1996: 134:8486.

12. Gleicher N: Antiphospholipid antibodies and reproductive failure: What they do and what they do not do: how to, and how not to treat! Hum Reprod 1997: 12:13-16.

13. Petri M. Allbritton J: Fetal outcome of lupus pregnancy: A retrospective case control study of the Hopkins Lupus Cohort. J Rheumatol 1993: 20:650-656.

14. Lee SS, Lawton JMW: Anti-myeloperoxidase antibody in systemic lupus erythematosus. J Intern Med 1992: 232:283-286.
15. Nassberger L. Sjoholm AG, Jarsson H. Sturfelt G. Akesson A: Antibodies against neutrophil cytoplasm components in systemic lupus erythematosus and in hydralazine-induced lupus. Clin Exp Immunol 1990: $81: 380-383$.

16. Coulam CB. Goodman C. Roussev RG. Thomason EJ. Beaman KD: Systemic CD56 + cells can predict pregnancy outcome. Am J Reprod Immunol 1995; 33:40-46.

17. Roussev RG. Kaider BD. Price DE. Coulam CB: Laboratory evaluation of women experiencing reproductive failure. Am J Reprod Immunol 1996; 35:415-420.

18. Berczi I: Prolactin, pregnancy and autoimmune disease. J Rheumatol 1993: 20:1095-1099.

19. Jin K. Ho HN, Speed TP, Gill III TJ: Reproductive failure and the major histocompatibility complex. Am J Hum Genet 1995: 56:1456-1467.

20. Swaak T. Smeenk R: Detection of anti-dsDNA as a diagnostic tool: A prospective study in 441 non-systemic lupus erythematosus patients with antidsDNA antibody (anti-dsDNA). Ann Rheum Dis 1985; 44:245-251.

21. Julkunen H. Kurki P. Kaaja R. Heikkila R. Immonen I. Chan EKL. Wallgren E, Friman C: Isolated congenital heart block: Long-term outcome of mothers and characterization of the immune response to SS-A/Ro and to SS-B La. Arthritis Rheum 1993: 36:1588-1598.

22. Peng SL. Madaio MP. Hayday AC. Craft J: Propagation and regulation of systemic autoimmunity by gamma-delta T cells. J Immunol 1996; 157:5689-5698.

23. Stekman IL, Blasini AM, Leon-Ponte M. Baroja ML, Abadi I, Rodriguez MA: Enhanced CD3-mediated T lymphocyte proliferation in patients with systemic lupus erythamatosus. Arthritis Rheum 1991; 34:459-467.

24. Fox DA, Millard A. Treisman J, Zeldes W, Bergman A, Depper J, Dunne R. McCune WJ: Defective CD2 pathway $T$ cell activation in systemic lupus erythematosus. Arthritis Rheum 1991: 34:561-571.

25. Amoura Z. Chabre H. Koutouzov S. Lotton C. Cabrespines A, Bach JF, Jacob L: Nucleosome-restricted antibodies are detected before anti-dsDNA and or antihistone antibodies in serum of MRL-Mp lpr $1 \mathrm{pr}$ and ++ mice, and are present in kidney eluates of lupus mice with proteinurea. Arthritis Rheum 1994: 37:1684-1688.

26. Gross WL: New concepts in Wegener's granulomatosis. In The Vasculitides, BM Ansell. PA Bacon. JT Lie. H Yazici (Eds). London, Chapman and Hall, 1996. pp. $145-171$. 